\title{
Análise de publicações sobre o tema Energia com enfoque CTS no Ensino de Ciências no Brasil entre 2006 e 2017
}

Analysis of publications on the topic of Energy with a STS focus on Science Teaching in Brazil between 2006 and 2017

Análisis de publicaciones sobre el tema Energía con enfoque CTS en la Enseñanza de las Ciencias en Brasil entre 2006 y 2017

\section{Resumo}

A finalidade desse artigo é apresentar e analisar as pesquisas que investigam o tema Energia abordado sob os pressupostos do movimento CTS (Ciência, Tecnologia e Sociedade) no Brasil no período entre 2006 e 2017. Foram identificados trinta trabalhos publicados em periódicos e anais de eventos, cuja análise permitiu identificar alguns aspectos categorizados em características gerais, natureza do trabalho e foco temático. Foi apurado que o Ensino Médio é o nível de escolarização que apresenta maior concentração da produção analisada e que há poucos trabalhos direcionados ao Ensino Fundamental e à formação de professores. A maioria dos trabalhos investigados compreende um leque de atividades didático-pedagógicas, utilizando sequências didáticas, onde o tema Energia foi apoiado no enfoque CTS. Espera-se com este estudo compreender melhor as pesquisas realizadas no campo da Educação em Ciências relacionadas ao tema Energia desenvolvido sob o enfoque CTS, fornecendo descrições e análises que permitam compreender melhor a formação e o desenvolvimento dessa área de pesquisa.

Palavras-chave: Ensino de ciências; Energia; Enfoque CTS; Ensino.

\begin{abstract}
The purpose of this article is to present and analyze the research that investigate the theme Energy addressed under the assumptions of the CTS (Science, Technology and Society) movement in Brazil between 2006 and 2017. Thirty papers published in periodicals and annals of events were identified, whose analysis allowed to identify some aspects categorized in general characteristics, nature of the work and thematic focus. It was found that the High School is the level of schooling that presents the highest concentration of production analyzed and that there are few jobs directed to Elementary School and teacher training. Most of the works investigated comprise a range of didactic-pedagogical activities, using didactic sequences, where the theme Energy was supported in the CTS approach. This study is expected to better understand the research carried out in the field of Science Education related to the topic Energy developed under the CTS approach, providing descriptions and analyzes that allow a better understanding of the training and development of this area of research.
\end{abstract}

Keywords: Science teaching; Energy; Approach CTS; Teaching.

\section{Resumen}

El propósito de este artículo es presentar y analizar la investigación que investiga el tema Energía abordado bajo los supuestos del movimiento CTS (Ciencia, Tecnología y Sociedad) en Brasil en el período 2006-2017. Treinta trabajos publicados en revistas y actas de eventos. Se identificaron, cuyo análisis permitió identificar algunos aspectos categorizados en características generales, naturaleza del trabajo y enfoque temático. Se encontró que Bachillerato es el nivel de escolaridad que presenta mayor concentración de la producción analizada y que existen pocos trabajos dirigidos a Bachillerato y formación docente. La mayoría de los trabajos investigados comprenden un abanico de actividades didáctico-pedagógicas, utilizando secuencias didácticas, donde el tema Energía fue apoyado por el enfoque CTS. Se espera que este estudio comprenda mejor la investigación realizada en el campo de la Educación Científica relacionada con el tema Energía desarrollada bajo el enfoque CTS, proporcionando descripciones y análisis que permitan una mejor comprensión de la formación y desarrollo de esta área de investigación.

Palabras clave: Enseñanza de las ciencias; Energía; Enfoque CTS; Enseñanza. 


\section{Introdução}

No Ensino de Ciências muitas pesquisas são realizadas com o propósito de apontar caminhos que permitam aperfeiçoar a educação científica nos diferentes níveis de ensino. Assim, o objetivo dessa pesquisa é apresentar e discutir algumas tendências das pesquisas brasileiras realizadas com base no enfoque CTS tendo como tema central a energia e as questões que a circundam tais como os processos de sua produção, a sustentabilidade e os problemas socioambientais publicadas em periódicos e anais de eventos científicos relacionados com a área de ensino.

Neste sentido Fernandes (2013) garante que:

É importante destacar que o tema Energia está fortemente presente em nossa vida cotidiana e também é frequentemente citado em conteúdos científicos, ganhando por isso, grande destaque no ensino das Ciências naturais e suas tecnologias (Fernandes, 2013, p. 2).

Considerando que as pesquisas envolvendo o enfoque CTS na Educação em Ciências gerou nos últimos anos diversas propostas relevantes para aperfeiçoar a formação dos estudantes, identificamos a necessidade de realizar investigações que permitam caracterizar os rumos da produção científica e acadêmica nesta área. Iniciativas neste sentido estiveram presentes em estudos anteriores como, por exemplo: Santos e Mortimer (2002), Cachapuz et al. (2008), que apresentaram revisões de literatura sobre a pesquisa CTS no contexto da Educação em Ciências; Strieder e Kawamura (2009) ao analisarem trabalhos apresentados nos ENPEC (Encontro Nacional de Pesquisa em Educação em Ciências); Hunsche et al. (2009) ao consultarem periódicos brasileiros da área de Educação em Ciências; e Auler, Dalmolin e Fenalti (2009) ao examinarem anais de eventos, coletâneas de cadernos de formação e guias didáticos.

Examinando os estudos mencionados, não encontramos pesquisas dedicadas ao mapeamento de produções acadêmicas em Educação em Ciências que tivessem como foco a abordagem do conceito de energia sob o enfoque CTS. A opção pelo mapeamento do tema "Energia" se justifica por ser abrangente e instigador de questões atuais e pertinentes ao entendimento das relações entre a Ciência, a Tecnologia e Sociedade, possibilitando refletir sobre a dimensão social inerente à abordagem CTS. Este fato nos direcionou para o desenvolvimento desta pesquisa, realizando um mapeamento de trabalhos publicados no Brasil, no período de 2006 a 2017.

Orientamos nossa investigação com a seguinte pergunta: O que sinalizam as pesquisas brasileiras em Educação em Ciências sobre o tema "Energia” embasadas nas diretrizes do enfoque Ciência, Tecnologia e Sociedade (CTS)?

Sendo assim, o objetivo desse trabalho foi identificar e analisar os estudos acadêmicos centrados na interface do enfoque CTS com o tema "Energia", visando descrever suas principais características de modo a evidenciar as tendências apresentadas por estas investigações.

Não se trata apenas de uma pesquisa de publicações ao longo do tempo, mas a busca de delineamento de um panorama amplo que favoreça a compreensão da aplicabilidade do enfoque CTS na Educação em Ciências, mostrando que esse aspecto tem enorme relevância para uma adequada formação de cidadãos responsáveis e participativos.

Segundo Bazzo (1998):

O cidadão merece aprender a ler e entender - muito mais do que conceitos estanques - a ciência e a tecnologia, com suas implicações e consequências, para poder ser elemento participante nas decisões de ordem política e social que influenciarão o seu futuro e o dos seus filhos (Bazzo, 1998, p. 34).

Visando alcançar os objetivos traçados foi analisado um total de trinta (30) trabalhos, divididos em artigos de periódicos e publicações em anais de congressos e encontros na área de Ensino e Educação em Ciências. 


\section{Metodologia}

Trata-se de uma pesquisa bibliográfica realizada através do conhecimento difundido na literatura especializada a partir do levantamento de referências teóricas publicadas por meios eletrônicos através de artigos científicos em periódicos e anais de eventos científicos. O tema utilizado foi "Energia", sua produção e utilização com enfoque CTS (Ciência, Tecnologia e Sociedade).

Segundo Prodanov e Freitas (2013), pesquisa bibliográfica é aquela que,

[...] elaborada a partir de material já publicado, constituído principalmente de: livros, revistas, publicações em periódicos e artigos científicos, jornais, boletins, monografias, dissertações, teses, material cartográfico, internet, com o objetivo de colocar o pesquisador em contato direto com todo material já escrito sobre o assunto da pesquisa (Prodanov e Freitas, 2013, p. 54).

De acordo com Fonseca (2002),

[...] pesquisa bibliográfica é feita a partir do levantamento de referências teóricas já analisadas, e publicadas por meios escritos e eletrônicos, como livros, artigos científicos, páginas de web sites. [...] pesquisas científicas que se baseiam unicamente na pesquisa bibliográfica, procurando referências teóricas publicadas com o objetivo de recolher informações ou conhecimentos prévios sobre o problema a respeito do qual se procura a resposta (Fonseca, 2002, p. $32)$.

Também, segundo Gil (2010), “a pesquisa bibliográfica é desenvolvida com base em material já elaborado” e sua principal vantagem,

[...] reside no fato de permitir ao investigador a cobertura de uma gama de fenômenos muito mais ampla do que aquela que poderia pesquisar diretamente. Essa vantagem torna-se particularmente importante quando o problema de pesquisa requer dados muito dispersos pelo espaço. Por exemplo, seria impossível a um pesquisador percorrer todo o território brasileiro em busca de dados sobre população ou renda per capita; todavia, se tem a sua disposição uma bibliografia adequada, não terá maiores obstáculos para contar com as informações requeridas. A pesquisa bibliográfica também é indispensável nos estudos históricos. Em muitas situações, não há outra maneira de conhecer os fatos passados se não com base em dados bibliográficos (Gil, 2010, p. 45).

Buscamos analisar os princípios e fundamentos apresentados na perspectiva de diferentes autores, visando recolher informações sobre as pesquisas realizadas no contexto da relação entre Energia e CTS.

\section{O enfoque CTS e o conceito de Energia}

Historicamente, o conhecimento da Ciência e da Tecnologia tomou corpo e se estabeleceu, sendo criada uma nova relação denominada desenvolvimento científico e tecnológico (Angotti \& Auth, 2001). Essa interação resultou nos artefatos e produtos, que influenciam o cotidiano das pessoas em diferentes níveis.

Bazzo et al. (2008), assegura que:

Todos os grupos que hoje vêm estudando tais questões são taxativos ao apontar que não se poderia pensar em qualquer remodelação ou melhoria de caráter reflexivo na educação sem a inclusão de estudos que contemplem os diversos aspectos da relação entre ciência, tecnologia e sociedade como parâmetro fundamental para a formação dos futuros cidadãos (Bazzo et al., 2008, p. 160).

Ao longo do tempo se constata uma veloz ampliação dessa área do conhecimento, com muitos artefatos sendo produzidos e utilizados em áreas como a Física, a Química e a Biologia, entre outras, gerando discussões e polêmicas quanto a 
essa produção. Isto nos leva a pensar sobre até onde é possível caminhar com todas essas inovações, sem danificar o ambiente em que vivemos. Também é conveniente indagar se este processo em curso deve ser considerado natural sem quaisquer questionamentos e percepções críticas acerca do mesmo.

Uma análise mais cuidadosa sobre o estudo da energia nos coloca, fatalmente, diante de uma diversidade que é própria do tema, pois envolve questões tecnológicas, econômicas, políticas, sociais, culturais e ambientais (Bernardo, 2008). Neste sentido revela-se relevante a identificação e estruturação do tema energia na perspectiva CTS, tendo como foco o tratamento do conceito de energia, considerando algumas fontes de publicação no Brasil, permitindo abordar possíveis danos ambientais e os aspectos sociopolíticos envolvidos no seu processo de geração, transmissão e uso.

Assis e Teixeira (2001) apontam que o conceito de energia está habitualmente inserido no contexto da conservação de energia. Os autores enfatizam que a abordagem no Ensino de Ciências está também relacionada às discussões de transformação de energia em seus diferentes processos e diversas formas. A tendência que acompanha o ensino da energia são as relações CTS (Assis \& Teixeira, 2001), relações estas que norteiam nosso presente estudo.

Estas autoras ressaltam ainda que há dificuldade no processo de ensino e aprendizagem do conceito de energia, sendo que essa dificuldade está no fato deste conceito ser complexo e abrangente, possibilitando ao longo de sua abordagem várias interpretações. Destacam também que a perspectiva CTS torna-se uma alternativa para o ensino deste tema de forma diversificada, facilitando o processo de ensino-aprendizagem do conceito de energia.

Santos e Mortimer destacam que,

A interação entre ciência, tecnologia e sociedade propiciaria o desenvolvimento de valores e ideias por meio de estudos de temas locais, políticas públicas e temas globais (Santos \& Mortimer, 2002, p. 115).

Angotti (1991) afirma que a energia é,

A grandeza que pode e deve, mais do que qualquer outra, balizar as tendências de ensino que priorizam hoje as relações entre Ciência-Tecnologia-Sociedade (CTS) (Angotti, 1991, p.115).

Neste sentido, mostra-se relevantes a identificação e a estruturação do tema energia no contexto do enfoque CTS, permitindo aos pesquisadores abordar o tema através de aspectos sociopolíticos envolvidos no seu processo de geração, transmissão e uso. Sendo assim, compreendemos a importância de se analisar pesquisas que relacionem o tema Energia relacionada ao enfoque CTS.

\section{Aspectos Metodológicos da Pesquisa}

Investigar artigos é um caminho natural a ser seguido, já que grande parte das investigações realizadas está associada a cursos de mestrado e doutorado, espaços que privilegiam a produção de conhecimento e que utilizam esse caminho para disseminar tais conhecimentos. De acordo com a própria CAPES, é no sistema nacional de Pós-Graduação que, fundamentalmente, ocorrem atividades de pesquisa científica e tecnológica no Brasil (CAPES, 2004). Sendo assim, essa produção é um sinal significativo daquilo que as instituições realizam enquanto pesquisa, especialmente nas áreas de Ensino e Educação em Ciências (Megid Neto, 1999).

A produção acadêmica ligada à área de Educação em Ciências na forma de artigos existe desde a década de 1970 e, ao longo dos anos, vem se estabelecendo como importante campo de pesquisa no cenário educacional do país. O período de abrangência de nossa pesquisa começa em 2006, e tem como marco final o ano de 2017, compreendendo assim onze anos para a coleta de dados junto aos sistemas de informação bibliográfica. 
A seleção dos artigos de interesse para a pesquisa foi realizada por meio das seguintes palavras-chave: CTS; Relações CTS; Energia; Estudo de Energia; Energia Elétrica; Energia Renovável; Ensino de Ciências; Educação em Ciências; Alfabetização Científica; Sustentabilidade.

As revistas e eventos que fizeram parte desta investigação foram selecionados por serem considerados representativos do conjunto de principais periódicos e eventos nacionais da área, com expressiva abrangência e relevância, levando em conta a relação entre o tema Energia e o enfoque CTS, sendo o conjunto analisado formado pelas fontes:

1. Caderno Brasileiro do Ensino de Física.

2. Revista Alexandria (A2).

3. Revista AMBIENTE \& EDUCAÇÃO (B1).

4. Revista ESC (Educação, Cultura e Sociedade) (B1).

5. Revista DMA (Desenvolvimento e Meio Ambiente) (B4).

6. Revista Ciência \& Ensino (B1).

7. Revista QNEsc (Química Nova na Escola) (B1).

8. Revista e-Mosaicos (Revista Multidisciplinar de Ensino, Pesquisa, Extensão e Cultura do Instituto de Aplicação Fernando Rodrigues da Silveira/CAp-UERJ) (B1).

9. Revista da SBEnBIO (Associação Brasileira de Ensino de Biologia) (B2).

10. Revista EENCI (Experiências em Ensino de Ciências) (B1).

11. EDUCERE - XIII Congresso Nacional de Educação.

12. Anais do VI, VII, VIII, IX e XI Encontro Nacional de pesquisa em Educação em Ciências (ENPEC).

13. Anais Do Encontro De Produção Discente PUCSP/Cruzeiro Do Sul.

14. Anais Do XVII, XVIII, XX E XXI Simpósio Nacional Do Ensino De Física (SNEF).

15. I Simpósio Nacional de Ensino de Ciência e Tecnologia.

Foram selecionados trabalhos em que os autores mencionaram explicitamente o enfoque CTS (ou CTSA) e o tema Energia ou que ao menos adotavam perspectivas de análise do problema que levassem em conta os pressupostos disseminados pela literatura ligada ao movimento CTS (Auler, 1998; Santos e Mortimer, 2002).

Ao final do processo de busca foram obtidos trinta (30) artigos que constituem o inventário empregado na análise desenvolvida neste trabalho, conforme mostra o Quadro 1.

Quadro 1: Síntese das produções mapeadas.

\begin{tabular}{|c|c|c|c|}
\hline TÍTULO & $\begin{array}{l}\text { PERIÓDICO/ } \\
\text { EVENTO }\end{array}$ & $\begin{array}{c}\text { ÁREA DE } \\
\text { CONCENTRAÇÃO }\end{array}$ & ANO \\
\hline 1. Um exercício de uso racional da energia: o caso do transporte coletivo. & $\begin{array}{l}\text { Caderno Brasileiro de } \\
\text { Ensino de Física }\end{array}$ & Ensino de Física & 2006 \\
\hline $\begin{array}{l}\text { 2. Energia, meio ambiente e desenvolvimento: Uma proposta didática para } \\
\text { alunos do Ensino Médio. }\end{array}$ & XVII SNEF & Ensino de Física & 2007 \\
\hline $\begin{array}{l}\text { 3. A energia elétrica na sala de aula do ensino médio: estratégias de } \\
\text { abordagens em Ciência- Tecnologia-sociedade (CTS). }\end{array}$ & VI ENPEC & Ensino de Ciências & 2007 \\
\hline $\begin{array}{l}\text { 4. As fontes de geração de energia e seus impactos socioambientais: a } \\
\text { educação ambiental como tema transversal interdisciplinar no Ensino } \\
\text { Médio. }\end{array}$ & XVIII SNEF & Ensino de Ciências & 2009 \\
\hline
\end{tabular}




\begin{tabular}{|c|c|c|c|}
\hline $\begin{array}{l}\text { 5. Energia e desenvolvimento humano: uma abordagem sociocientífica no } \\
\text { ensino de Ciências. }\end{array}$ & VII ENPEC & Ensino de Ciências & 2009 \\
\hline 6. Ensino de eletricidade através de campanha de economia de energia. & XVIII SNEF & Ensino de Física & 2009 \\
\hline 7. Energia Elétrica: uma sugestão de atividade para despertar a cidadania. & $\begin{array}{l}\text { I Simpósio Nacional de } \\
\text { Ensino de Ciência e } \\
\text { Tecnologia. }\end{array}$ & Ensino de Ciências & 2009 \\
\hline $\begin{array}{l}\text { 8. Relações Ciência-Tecnologia-Sociedade na abordagem do tema energia: } \\
\text { uma investigação na sala de aula do ensino médio. }\end{array}$ & XVIII SNEF & Ensino de Física & 2009 \\
\hline $\begin{array}{l}\text { 9. O estudo de energia: uma experiência de ensino na perspectiva CTS e o } \\
\text { uso de mídias. }\end{array}$ & $\begin{array}{l}\text { EENCI - Experiências em } \\
\text { Ensino de Ciências }\end{array}$ & Ensino de Física & 2010 \\
\hline $\begin{array}{l}\text { 10. Alfabetização científica e tecnológica e CTS numa ilha de racionalidade } \\
\text { sobre consumo consciente de energia elétrica. }\end{array}$ & VIII ENPEC & Ensino de Ciências & 2011 \\
\hline $\begin{array}{l}\text { 11. Introduzindo temas sociocientíficos na sala e aula: um estudo de caso } \\
\text { envolvendo produção de energia elétrica, desenvolvimento e ambiente. }\end{array}$ & VIII ENPEC & Ensino de Ciências & 2011 \\
\hline $\begin{array}{l}\text { 12. Ciência e Tecnologia na Escola: Desenvolvendo Cidadania por meio do } \\
\text { Projeto "Biogás - Energia Renovável para o Futuro". }\end{array}$ & Revista QNEsc & Ensino de Ciências & 2011 \\
\hline $\begin{array}{l}\text { 13. Abordagem do tema controverso Radioatividade/Energia Nuclear em } \\
\text { sala de aula no Ensino Médio - Um Estudo de Caso. }\end{array}$ & VIII ENPEC & Ensino de Ciências & 2011 \\
\hline $\begin{array}{l}\text { 14. Fontes Alternativas de Energia Automotiva no Ensino Médio } \\
\text { Profissionalizante: análise de uma proposta contextualizada de ensino de } \\
\text { Física em um curso técnico. }\end{array}$ & Revista ALEXANDRIA & Ensino de Ciências & 2012 \\
\hline $\begin{array}{l}\text { 15. O tema energia e a perspectiva Ciência-Tecnologia-Sociedade (CTS) no } \\
\text { Ensino de Física: possíveis articulações nos documentos oficiais } \\
\text { curriculares. }\end{array}$ & IX ENPEC & Ensino de Física & 2013 \\
\hline $\begin{array}{l}\text { 16. As fontes de energia do Brasil: uma atividade com enfoque CTS em } \\
\text { uma sala de aula do EJA. }\end{array}$ & XX SNEF & Ensino de Física & 2013 \\
\hline $\begin{array}{l}\text { 17. Produção de energia elétrica em larga escala: uma proposta de ACT em } \\
\text { sala de aula. }\end{array}$ & XX SNEF & Ensino de Física & 2013 \\
\hline $\begin{array}{l}\text { 18. Energia Nuclear no Ensino Médio: desenvolvendo atividades didáticas } \\
\text { com enfoque CTSA - uma possibilidade para a formação da cidadania. }\end{array}$ & IX ENPEC & Ensino de Ciências & 2013 \\
\hline 19. Energia e conflitos socioambientais: consumo e sociedade. & $\begin{array}{l}\text { AMBIENTE \& } \\
\text { EDUCAÇÃO }\end{array}$ & $\begin{array}{l}\text { Educação em } \\
\text { Ciências }\end{array}$ & 2014 \\
\hline $\begin{array}{l}\text { 20. Energias, Transformações e Tecnologias: desenvolvimento de uma } \\
\text { sequência didática. }\end{array}$ & Revista da SBEnBIO & Ensino de Ciências & 2014 \\
\hline $\begin{array}{l}\text { 21. Abordagem contextualizada do conceito de energia utilizando enfoque } \\
\text { CTSA. }\end{array}$ & $\begin{array}{l}\text { Anais do Encontro de } \\
\text { Produção Discente } \\
\text { PUCSP/Cruzeiro do Sul }\end{array}$ & Ensino de Ciências & 2014 \\
\hline $\begin{array}{l}\text { 22. A produção de energia elétrica em larga escala no Brasil: uma } \\
\text { abordagem CTS para o ensino médio. }\end{array}$ & $\begin{array}{l}\text { Educação, Cultura e } \\
\text { Sociedade. }\end{array}$ & Ensino de Física & 2014 \\
\hline $\begin{array}{l}\text { 23. Energia como tema de estudo e valorização da comunidade como } \\
\text { consequência. }\end{array}$ & Ciência \& Ensino & Ensino de Física & 2014 \\
\hline $\begin{array}{l}\text { 24. Seminário como ferramenta para aprendizagem significativa de } \\
\text { conceitos de energia utilizando o enfoque CTS/CTSA. }\end{array}$ & XXI SNEF & Ensino de Física & 2015 \\
\hline $\begin{array}{l}\text { 25. A temática energia e vida: articulação de pressupostos CTS nas aulas de } \\
\text { Ciências no ensino fundamental. }\end{array}$ & Revista da SBEnBIO & Ensino de Ciências & 2016 \\
\hline
\end{tabular}




\begin{tabular}{|c|c|c|c|}
\hline $\begin{array}{l}\text { 26. Energia, água e relações entre Ciência, Tecnologia, Sociedade e } \\
\text { Ambiente no ensino de ciências: interações discursivas e possibilidades } \\
\text { formativas. }\end{array}$ & $\begin{array}{l}\text { Desenvolvimento e Meio } \\
\text { Ambiente }\end{array}$ & $\begin{array}{l}\text { Educação em } \\
\text { Ciências }\end{array}$ & 2016 \\
\hline $\begin{array}{l}\text { 27. Proposta de abordagem temática com enfoque CTS no ensino de Física: } \\
\text { produção de energia elétrica. }\end{array}$ & Revista e-Mosaicos & Ensino de Física & 2016 \\
\hline $\begin{array}{l}\text { 28. Ensino de Ciências e CTS: Contribuições ao Aperfeiçoamento de } \\
\text { Situações de Aprendizagem sobre Entropia e Degradação de Energia. }\end{array}$ & ALEXANDRIA & Ensino de Ciências & 2016 \\
\hline $\begin{array}{l}\text { 29. O estudo da Energia com enfoque CTS, fundamentado no } \\
\text { documentário POWER. }\end{array}$ & XI ENPEC & $\begin{array}{l}\text { Educação em } \\
\text { Ciências }\end{array}$ & 2017 \\
\hline $\begin{array}{l}\text { 30. Ciência, tecnologia, sociedade, ambiente e energia elétrica: implicações } \\
\text { de processos de problematização no ensino médio. }\end{array}$ & $\begin{array}{l}\text { EDUCERE - XIII } \\
\text { Congresso Nacional de } \\
\text { Educação }\end{array}$ & $\begin{array}{l}\text { Educação em } \\
\text { Ciências }\end{array}$ & 2017 \\
\hline
\end{tabular}

Fonte: Autores.

\section{Apresentação e Análise dos Resultados}

A leitura cuidadosa dos trabalhos permitiu, por meio de uma abordagem quali-quantitativa ou abordagem mista, realizar análises destas publicações.

Segundo Creswell (2007), essa abordagem decorre da necessidade de reunir dados quantitativos e qualitativos na coleta e análise de dados em um determinado estudo. O processo de coleta de dados, a partir de procedimentos mistos (qualiquantitativos), envolve dados numéricos ou estatísticos, bem como informações textuais.

É uma abordagem da investigação que combina ou associa as formas qualitativa e quantitativa. Envolve suposições filosóficas, o uso de abordagens qualitativas e quantitativas e a mistura das duas abordagens em um estudo. Por isso, é mais do que uma simples coleta e análise dos dois tipos de dados; envolve também o uso das duas abordagens em conjunto, de modo que a força geral de um estudo seja maior do que a da pesquisa qualitativa ou quantitativa isolada (Creswell, 2007, p. 27).

A abordagem quali-quantitativa nos parece apropriada nesse contexto, para que possamos expandir o entendimento de um método para outro, para convergir e confirmar resultados de nossas fontes de dados.

Essa abordagem quali-quantitativa resultou no desenvolvimento de uma classificação que envolve categorias, visto que:

A categorização é uma operação de classificação de elementos constitutivos de um conjunto por diferenciação e, em seguida, por reagrupamento segundo o gênero (analogia), com os critérios previamente definidos. As categorias são rubricas ou classes, as quais reúnem um grupo de elementos (unidades de registro, no caso da análise de conteúdo) sob um título genérico, agrupamento esse efetuado em razão das características comuns destes elementos. (Bardin, 2011, p. 147)

Foram definidas a priori as seguintes categorias:

1) Características gerais: envolvem o ano de publicação ou de realização do evento, evolução quantitativa da produção e nível escolar privilegiado nas pesquisas;

2) Natureza dos trabalhos: foi analisado se são trabalhos teóricos, observações e relatos ou intervenções;

3) Foco temático primário: especifica o tema ou assunto, objeto de investigação e estudo nos trabalhos - Energia/CTS propiciando desdobramentos em focos temáticos secundários - Ensino-aprendizagem, Sequência e/ou Material didático, Currículos e Programas, Experimentação e História da Ciência (Kawasaki, et al, 2009). 


\section{1) Características Gerais}

Do grupo de trinta (30) trabalhos analisados, vinte e um (21) tem sua área de concentração voltada ao Ensino Médio, cinco (5) ao Ensino Fundamental, três (3) são trabalhos produzidos com vistas à formação de professores e um (1) ligado ao estudo de documentos oficiais no que tange a perspectiva CTS relacionado ao ensino de Física.

Identificamos cronologicamente todos os anos que compõem o intervalo investigado (Quadro 2), embora a frequência dessas publicações varie bastante a cada ano, sendo que não encontramos nenhuma publicação no ano de 2008.

Quadro 2 - Produção de trabalhos por ano.

\begin{tabular}{|c|c|c|c|c|c|c|c|c|c|c|c|}
\hline Ano & 2006 & 2007 & 2008 & 2009 & 2010 & 2011 & 2012 & 2013 & 2014 & 2015 & 2016 \\
\hline Quantidade & 1 & 2 & 0 & 5 & 1 & 4 & 1 & 4 & 5 & 1 & 2 \\
\hline
\end{tabular}

Fonte: Autores.

Nos anos de 2009 e 2014 (5 trabalhos em cada ano), 2011, 2013 e 2016 (4 trabalhos em cada ano) a produção de trabalhos envolvendo o estudo da energia com enfoque CTS apresenta-se em maior escala. Portanto, não se verifica uma produção razoavelmente constante de trabalhos envolvendo energia e enfoque CTS no período e fontes investigadas, não se observando ainda uma tendência temporal definida, apesar da relevância deste tema.

Essa grande variação no número de publicações contrasta com os processos de expansão e diversificação da PósGraduação no setor educacional, sendo verificada uma consolidação e relevância da pesquisa em Educação em Ciências no país nos últimos anos (Pinheiro; Silveira; Bazzo, 2007). Esta ampliação provavelmente levou à diversificação de temas investigados e não há uma ampliação das produções relacionadas com o enfoque CTS em estudos sobre a energia.

De qualquer forma, parece ainda muito modesta a quantidade de trabalhos com orientação CTS nos estudos acadêmicos vinculados com a Educação em Ciências tendo como tema central a Energia.

Ao examinarmos a distribuição dos trinta (30) estudos selecionados, constata-se que os trabalhos pesquisados foram publicados em revistas, anais de encontros de pesquisa e produção discentes, simpósios e seminários (Quadro 3). 
Quadro 3 - Revistas e Arquivos identificados.

\begin{tabular}{|c|c|c|}
\hline Periódico/Evento & Tipo & Quantidade de artigos \\
\hline Ciência \& Ensino & Revista & 2 \\
\hline Caderno Brasileiro de Ensino de Física & Revista & $\mathbf{1}$ \\
\hline Alexandria & Revista & 2 \\
\hline Ambiente \& Educação & Revista & 1 \\
\hline Educação, Cultura e Sociedade & Revista & 1 \\
\hline Desenvolvimento e Meio Ambiente & Revista & 1 \\
\hline QNEsc (Química Nova na Escola) & Revista & 1 \\
\hline e-Mosaicos & Revista & 1 \\
\hline $\begin{array}{c}\text { Revista da SBEnBIO (Associação Brasileira de } \\
\text { Ensino de Biologia) }\end{array}$ & Revista & 2 \\
\hline Experiências em Ensino de Ciências & Revista & 1 \\
\hline $\begin{array}{l}\text { Encontro Nacional de pesquisa em Educação em } \\
\text { Ciências }\end{array}$ & Anais de evento & 8 \\
\hline $\begin{array}{l}\text { Encontro de Produção Discente PUCSP/Cruzeiro } \\
\text { do Sul. }\end{array}$ & Anais de evento & 1 \\
\hline Simpósio Nacional do Ensino de Física & Anais de evento & 7 \\
\hline $\begin{array}{c}\text { Simpósio Nacional de Ensino de Ciência e } \\
\text { Tecnologia }\end{array}$ & Anais de evento & 1 \\
\hline $\begin{array}{c}\text { EDUCERE - XIII Congresso Nacional de } \\
\text { Educação }\end{array}$ & Anais de evento & 1 \\
\hline Total & - & 30 \\
\hline
\end{tabular}

Fonte: Autores.

A maior incidência de artigos acontece no Encontro Nacional de pesquisa em Educação em Ciências (ENPEC) e no Simpósio Nacional do Ensino de Física (SNEF), que totalizam quinze (15) documentos. Isto mostra a importância desses eventos como espaços para a disseminação dos trabalhos produzidos pelos pesquisadores no que se refere à abordagem da energia sob o enfoque CTS.

Foi detectada uma preponderância de estudos dedicados ao Ensino Médio, ou seja, vinte (20) trabalhos, correspondendo a dois terços dos trabalhos pesquisados. Essa predominância não é surpreendente, uma vez que boa parte das pesquisas em Educação em Ciências envolvendo o conceito de energia se relaciona a problemas que envolvem o ensino e a aprendizagem de conteúdos de Física, Química ou Biologia, disciplinas que são ministradas em escolas deste nível de escolarização. Assim, estes espaços se mostram privilegiados para que estas abordagens ocorram nestas disciplinas que compõem a grade curricular da Educação Básica.

\section{2) Natureza do trabalho}

Examinando os trabalhos desenvolvemos uma classificação baseada na natureza do estudo realizado, conforme segue:

- Natureza teórica: nestes trabalhos há ausência de dados empíricos, havendo apresentação, discussão e reflexão de pressupostos e referências teóricas relacionadas ao movimento CTS.

- Observações e relatos: as pesquisas são relatadas envolvendo a coleta de dados, mas se verifica ausência de intervenções na realidade, ou seja, as pesquisas investigam concepções e práticas/atitudes de professores e alunos, examinam materiais didáticos e outros recursos e analisam propostas curriculares. 
- Intervenção: a pesquisa descrita associa uma ação ou propostas de implantação de pressupostos CTS em situações específicas de sala-de-aula.

No conjunto dos trinta documentos identificamos três (3) estudos teóricos, dois estudos (2) caracterizados como pesquisas de observações e relatos e vinte e cinco (25) estudos associados à metodologia de intervenção que foram concretizados através de sequências ou materiais didáticos.

No próximo item, ao apresentarmos os focos temáticos, faremos uma descrição específica dos aspectos envolvidos nessas dimensões dos estudos acadêmicos.

\section{3) Foco temático primário (Energia/CTS)}

No contexto do foco temático primário foram identificados focos temáticos secundários, que foram divididos nas seguintes categorias: Ensino-aprendizagem, Sequência e/ou Material didático, Currículos e Programas, Experimentação e História da Ciência.

a) Ensino-aprendizagem - caracterizada pela investigação das relações entre professor e aluno, tanto em sala de aula como em espaços não formais de aprendizagem. Foram observados nove (9) trabalhos destinados ao estudo dos conhecimentos dos estudantes acerca de temas sociais (conceitos e conteúdo) e as relações com o seu cotidiano; a problematização das relações CTS em sala de aula; aspectos de educação ambiental; além de estudos teóricos e possibilidades de ensino sob o enfoque CTS.

b) Sequência e/ou Material didático - os quinze (15) trabalhos encontrados visam investigar a organização de conceitos, conteúdos, materiais e experiências didáticas, com o objetivo de favorecer os processos de ensino e aprendizagem com propostas didáticas e metodológicas voltadas ao estudo do tema energia com ênfase em CTS; bem como educação cientifica e alfabetização científica.

c) Currículos e Programas - os estudos apresentam as diversas maneiras de elaborar e organizar os programas das componentes curriculares, sendo enfatizada a interdisciplinaridade no currículo, a leitura de textos sobre fontes e produção de energia; bem como configurações curriculares relacionadas à energia e transporte (particular versus coletivo). Encontramos quatro (4) trabalho com essas características.

d) Experimentação - a característica principal é a utilização de atividades experimentais com o objetivo de promover mudanças no ensino de Ciências, substituindo a tradicional prática de transmissão e recepção de conhecimentos por outra mais próxima da pesquisa científica e do trabalho investigativo, sendo propostas oficinas experimentais e metodologia de resolução de problemas. Com essas características encontramos dois (2) trabalhos.

O Quadro 4 apresenta os quantitativos de artigos investigados segundo as categorias relacionadas aos focos temáticos secundários.

Quadro 4 - Focos temáticos secundários apresentados nas produções analisadas no período de 2006 a 2016.

\begin{tabular}{|l|c|c|c|}
\hline \multicolumn{1}{|c|}{ Foco temático secundário } & Quantidade & $\%$ & Número do trabalho (Tabela 1) \\
\hline Ensino-aprendizagem & 9 & 30 & $\mathbf{8 , 1 0 , 1 3 , 1 4 , 1 7 , 2 1 , 2 2 , 2 4 , 2 5}$ \\
\hline Currículos e Programas & 4 & 13 & $\mathbf{3 , 5 , 1 5 , 1 9}$ \\
\hline Experimentação & 2 & 7 & 12,28 \\
\hline $\begin{array}{l}\text { Sequência e/ou material } \\
\text { Didático }\end{array}$ & 15 & 50 & $1,2,4,6,7,9,11,16,18,20,23,26,27,29,30$ \\
\hline Total & 30 & 100 & \\
\hline
\end{tabular}

Fonte: Autores.

De acordo com o quadro, observamos que há uma predominância de trabalhos sobre "Sequência e/ou material Didático", quinze (15) trabalhos, correspondendo a $50 \%$ do total. 
Acreditamos que, por meio deste tipo de estratégia, haja avanço na apropriação do conhecimento, e que por meio dela, seja possível ensinar qualquer tema e conteúdo, propiciando aos discentes uma maior reflexão e apreensão acerca do ensino proposto, onde os conhecimentos adquiridos sejam levados à vida dos estudantes e não somente naquele momento da aula ou da avaliação.

\section{Considerações Finais}

Entendemos que o tema energia pode ser empregado como um estruturador na Educação em Ciências e que sua abordagem pode e deve estar acompanhada de aspectos socioambientais envolvidos nos processos de sua produção e utilização, o que gera abertura para o desenvolvimento de propostas alinhadas à perspectiva CTS.

Neste sentido, são pertinentes as abordagens identificadas em alguns trabalhos analisados que buscavam identificar as diferentes fontes de energia e os processos de transformação presentes na sua produção para uso social, bem como aqueles trabalhos que enfatizavam os impactos ambientais gerados por esta produção e uso da energia. Estas abordagens propiciavam reflexões acerca das escolhas de diferentes fontes de energia em função de critérios de sustentabilidade. Cabe destacar os trabalhos que buscavam acompanhar a evolução dos sistemas de produção e do consumo social de energia, relacionando-os ao desenvolvimento econômico, tecnológico e a qualidade de vida da população ao longo do tempo (Brasil, 2002).

Em seu conjunto, os trabalhos investigados pautados pelos pressupostos CTS no período considerado de 2006 a 2017 mostram indicativos promissores quanto aos reflexos que as abordagens podem ocasionar no ensino e na aprendizagem de Ciências. Apresentamos aqui um mapeamento de publicações vinculadas ao ensino de Ciências que discutem o tema energia a partir de abordagens baseadas nos pressupostos do movimento CTS. Consideramos que as implicações éticas, ambientais, sociais e econômicas são aspectos de grande relevância na formação para a cidadania e que essas implicações devem fazer parte do cotidiano do aluno, em especial na abordagem do tema sugerido por apresentar inúmeras conexões com a sociedade, com os sistemas produtivos e com aspectos ambientais.

O número de produções encontradas e analisadas pode ser considerado ainda pequeno, sinalizando o quanto o tema energia com enfoque CTS é ainda pouco explorado, sobretudo em estudos que englobem o currículo de Ciências no Ensino Médio. São predominantes as pesquisas de intervenção. No entanto, algumas poucas pesquisas com observações e relatos vinculadas a processos de descrição interpretativa também apareceram. Contudo, elas representam experiências que focam aspectos pontuais dos conteúdos ministrados, revelando uma eventual introdução do conteúdo sob o enfoque CTS.

Apesar da predominância da participação de trabalhos de intervenção nos ambientes escolares, ainda percebemos o quanto o enfoque CTS pode se mostrar como um grande desafio para os docentes, que, em geral são inexperientes neste tipo de proposta educacional, pois a mesma demanda posturas bastante diferenciadas no que diz respeito à organização das discussões que devem aflorar nas aulas, com nítidos impactos sobre a relação entre o professor e o aluno. Mudanças também são exigidas no que se refere aos recursos instrucionais empregados e ao estímulo para que os estudantes assumam atitudes investigativas e participativas que favoreçam a construção de novos conhecimentos.

Via de regra se constata que os estudantes estão acostumados a abordagens tradicionais que demandam menos envolvimento e participação em atividades que tendem a estimular a reflexão e o pensamento crítico, inerentes ao exercício da cidadania. Deste modo, o enfoque CTS constitui também para eles um desafio a ser enfrentado, com grande potencial para ampliar as possibilidades formativas dos mesmos.

Assim, se verifica que é preciso intensificar a produção de pesquisas nessa área, visando à efetivação do enfoque CTS de modo a não se limitar a pequenas sequências didáticas, mas sim buscando abordagens mais amplas e ricas em elementos formativos. De qualquer forma, observarmos que o campo CTS no país está gradativamente em desenvolvimento e consideramos que os resultados observados podem ser entendidos como animadores, pois sinalizam que pesquisadores e 
docentes têm caminhado no sentido de realizar propostas contemporâneas capazes de propiciar inovações curriculares relacionadas ao enfoque CTS.

Acreditamos que outras pesquisas complementares devam ser feitas com vistas a identificar pontos de convergência e de divergência no que diz respeito às diferentes práticas educacionais na perspectiva CTS, facilitando análises acerca da forma como as relações entre os diversos temas e conteúdos vêm sendo efetivamente abordadas dentro desse enfoque.

Acreditamos ser importante no momento atual o aprofundamento e a diversificação de análises sobre os caminhos a serem seguidos na Educação em Ciências, principalmente no que diz respeito à busca de maior qualidade na formação educacional dos estudantes. Esta busca deve se dar por meio de práticas docentes diferenciadas e que gerem não apenas maior aprendizagem conceitual dos conteúdos científicos nos estudantes, mas fundamentalmente o desenvolvimento de valores e atitudes convergentes com as demandas da sociedade moderna, particularmente quando consideramos os dilemas e problemas que a afligem.

Finalmente, esperamos que nossa pesquisa sirva de inspiração, a fim de que profissionais da área de Ciências possam empreender ações didático-metodológicas e realizar pesquisas que apresentem um alcance formativo cada vez mais amplo, favorecendo uma dimensão menos conservadora e mais humanista através do enfoque CTS, em abordagens de conteúdos científicos e tecnológicos.

\section{Referências}

Angotti, J. A. P. (1991). Fragmentos e totalidades no conhecimento científico e no ensino de Ciências. Tese de Doutorado. Faculdade de Educação da Universidade de São Paulo.

Angotti, J. A. P., \& Auth, M. A. (2001). Ciência e Tecnologia: implicações sociais e o papel da Educação. Ciência \& Educação, 7(1), 15-27.

Auler, D. (1998). Movimento Ciência-Tecnologia-Sociedade (CTS): modalidades, problemas e perspectivas em sua implementação no ensino de Física. In: Encontro de Pesquisa em Ensino de Física. Florianópolis. Anais. SBF, 268-271.

Auler, D.; Dalmolin, A. M. T. \& Fenalti, V. S. (2009). Abordagem temática: natureza dos temas em Freire e no enfoque CTS. Alexandria: Revista de Educação em Ciências e Tecnologia, 2 (1), 67-84.

Bardin, Laurence (2011). Análise de Conteúdo. Edições 70.

Bazzo, W.A., Pereira, L.T.V. \& Von Linsingen, I. (2008). Educação Tecnológica Enfoques para o Ensino de Engenharia. Editora da UFSC.

Benjamin, Alice Assis \& Teixeira, Odete P.B. (2001). Análise do Uso de um Texto Paradidático Sobre Energia e Meio Ambiente. Revista Brasileira de Ensino de Física, 23(1), 74-82.

Bernardo, J. R. R. (2008). A construção de estratégias para abordagem do tema Energia a luz do enfoque Ciência-Tecnologia - Sociedade (CTS) junto a professores de Física do ensino médio. Tese (Doutorado em Ensino de Biociências e Saúde) - Instituto Oswaldo Cruz.

Brasil (2002). Orientações Educacionais Complementares aos Parâmetros Curriculares Nacionais (PCN+), Ensino Médio, Ciências da Natureza, Matemática e suas Tecnologias. MEC.

Cachapuz, A; Paixão, F; Bernardino Lopes, J \& Guerra, C. (2008). Do estado da arte da pesquisa em Educação em Ciências: linhas de pesquisa e o caso "Ciência-Tecnologia-Sociedade". Alexandria: Revista de Educação em Ciência e Tecnologia, 1 (1), 27 - 49.

CAPES-Mec. (2004). Plano Nacional de Pós-Graduação (PNPG): 2005-2010. MEC/CAPES.

Creswell, J. W. (2007). Projeto de pesquisa: métodos qualitativo, quantitativo e misto. Artmed.

Fernandes, J. P. (2013) O tema energia e a perspectiva Ciência-Tecnologia-Sociedade (CTS) no Ensino de Física: possíveis articulações nos documentos oficiais curriculares. Atas do IX Encontro Nacional de Pesquisa em Educação em Ciências - IX ENPEC.

Fonseca, J. J. S. (2002) Metodologia da pesquisa científica. UEC.

GIL, Antonio Carlos (2010). Como elaborar projetos de pesquisa. Atlas.

Hunsche, S. et al. (2009). O enfoque CTS no contexto brasileiro: caracterização segundo periódicos da área de Educação em Ciências. In: Encontro Nacional de Pesquisa em Educação em Ciências, 7. Atas. ABRAPEC.

Kawasaki, C. S. et al. (2009). A pesquisa em educação ambiental nos ENPECS: contextos educacionais e focos temáticos. In: Encontro Nacional de Pesquisa em Educação em Ciências. Atas. VII ENPEC. 
Research, Society and Development, v. 10, n. 11, e160101119556, 2021

(CC BY 4.0) | ISSN 2525-3409 | DOI: http://dx.doi.org/10.33448/rsd-v10i11.19556

Megid Neto, J. (1999). Tendências da pesquisa acadêmica sobre o ensino de Ciências no nível fundamental. Campinas/SP, FE, Universidade Estadual de Campinas. Tese (Doutorado em Educação).

Minayo, Maria Cecília de Souza (Org.) (1994). Pesquisa social: Teoria, Método e Criatividade. Vozes.

Moraes, J. U. P. \& Araújo, M. S. T. (2012). O Ensino de Física e o Enfoque CTSA: caminhos para uma educação cidadã. Livraria da Física.

Pinheiro, N. A. M. \& Silveira, R. M. C. F.; \& Bazzo, W. A. (2007). Ciência, Tecnologia e Sociedade: A Relevância do enfoque CTS para o Contexto do Ensino Médio. Ciência \& Educação, 13, 71-84.

Prodanov, C. C. \& Freitas, E. C. (2013) Metodologia do trabalho científico: métodos e técnicas da pesquisa e do trabalho acadêmico. Feevale.

Santos, W. L. P. \& Mortimer, E. F. (2002). Uma análise de pressupostos teóricos da abordagem C-T-S (Ciência - Tecnologia - Sociedade) no contexto da educação brasileira. Ensaio, 2 (2), 1-23.

Strieder, R. \& Kawamura, M. R. (2009). Panorama das pesquisas pautadas por abordagens CTS. In: Encontro Nacional de Pesquisa em Educação em Ciências, 7, 2009. Atas. ABRAPEC. 